\title{
Dosimetry Calculations of Radiopharmaceuticals
}

Kelbe Jahnke

University of South Florida

\begin{abstract}
Advisors:
Arcadii Grinshpan, Mathematics and Statistics

Myriam Chaves, Radiation Dosimetrist, C. Gordon Griffith Comprehensive Cancer Center, Miami,
\end{abstract} $\mathrm{FI}$

Problem Suggested By: Myriam Chaves

Follow this and additional works at: https://digitalcommons.usf.edu/ujmm

Part of the Mathematics Commons

UJMM is an open access journal, free to authors and readers, and relies on your support: Donate Now

\section{Recommended Citation}

Jahnke, Kelbe (2010) "Dosimetry Calculations of Radiopharmaceuticals," Undergraduate Journal of Mathematical Modeling: One + Two: Vol. 3: Iss. 1, Article 7.

DOI: http://dx.doi.org/10.5038/2326-3652.3.1.19

Available at: https://digitalcommons.usf.edu/ujmm/vol3/iss1/19 


\title{
Dosimetry Calculations of Radiopharmaceuticals
}

\begin{abstract}
The goal of this project is to determine the absorbed dose of radiation to a patient using ${ }^{99 m}$ Tc-MAA as a tracer for a lung scan using the MIRD formula accounting only for the radiation dose contributed by the target organ. The radiation dose for other organs to the target organ is considered negligible as the uptake of ${ }^{99 \mathrm{~m}}$ Tc-MAA from other organs is less than $1 \%$. In addition to calculating the absorbed dose of radiation, the initial dose rate was also calculated by back solving to determine the total mass of the lungs. The radiation dose to the patient by the target organ was calculated to be 269.44 mrads and the initial dose rate was determined to be $156 \mathrm{mrads} / \mathrm{hr}$.
\end{abstract}

\section{Keywords}

Radiopharmaceuticals, Absorbed Radiation Dose, Positron Emission Tomography

Creative Commons License

(c) (i) $\Theta$

This work is licensed under a Creative Commons Attribution-Noncommercial-Share Alike 4.0 License.

\section{Erratum}

This article was previously called Article 19. 


\section{TABLE OF CONTENTS}

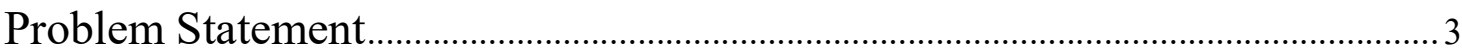

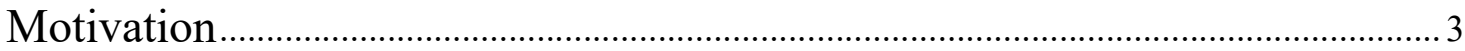

Mathematical Description and Solution Approach ................................................. 4

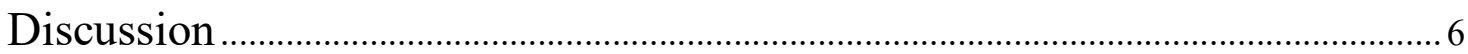

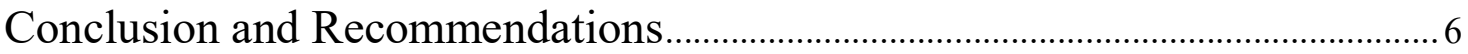

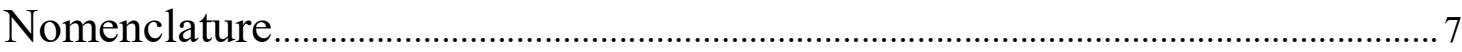

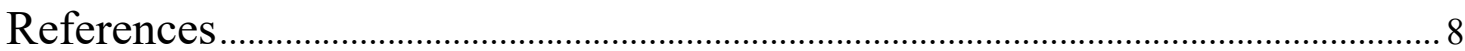

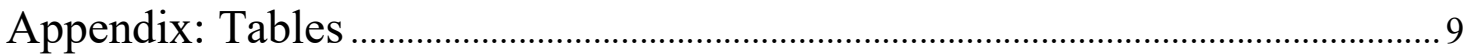




\section{PROBLEM STATEMENT}

Calculate the absorbed dose to the lungs of an adult patient who received $3 \mathrm{mCi}(111 \mathrm{MBq})$ ${ }^{99 \mathrm{~m}}$ Tc-MAA, assuming 99\% uptake and uniform distribution of the radioactivity in the lungs. Pertinent data are: $T_{b}=1.5 \mathrm{hr}$ and $S=5.25 \times 10^{-5} \frac{\mathrm{rad}}{\mu C i \cdot h r}=0.0142 \frac{G_{y}}{G B q \cdot h r}$. (Saha 199)

1. Calculate the absorbed dose of radiation from the target organ.

2. Calculate the initial dose rate.

\section{Motivation}

The calculation of absorbed radiation is crucial for the safety of both the patient and the nuclear medical technician. Radiation overdose risks include vomiting, damage to the hematopoietic system, and death (Saha 199). These risks associated with the stages and dose ranges are outlined in Table 1 in the Appendix. Radiopharmaceuticals have multiple uses. They can be used as tracers for Positron Emission Tomography (PET), studies to determine factors such as certain metabolisms, and absorption and as treatment for certain diseases and conditions. The problem listed above would be a typical dose to a male patient undergoing a PET scan of the lungs to detect a pulmonary embolism. However, the hand calculation of radiation dosing has become essentially obsolete due to the use of computer programs that account for additional variables that differ from patient to patient. 


\section{MATHEMATICAL DESCRIPTION AND SOLUTION APPROACH}

The Medical Internal Radiation Dose (MIRD) formula is an equation that can be used to determine the dose of radiation to a patient using physical and biological factors such as the radioactivity of the source, the source's effective half-life, target organ mass, as well as many other factors determined by the Society of Nuclear Medicine. The effective half-life $T_{e}$ of the ${ }^{99 \mathrm{~m}} \mathrm{Tc}$ source must first be calculated to determine the dose formula. This is done by considering that the effective decay constant is given by $\lambda_{e}=\lambda_{p}+\lambda_{b}$, where $\lambda_{p}$ and $\lambda_{b}$ are the physical and biological decay constants respectively. Since any decay-constant is equal to the factor $\ln 2$ times the reciprocal of the half-life, the effective decay constant formula may be rewritten as

$$
\lambda_{e}=\lambda_{p}+\lambda_{b} \rightarrow \frac{1}{T_{e}}=\frac{1}{T_{p}}+\frac{1}{T_{b}}
$$

The physical half-life of ${ }^{99 \mathrm{~m}} \mathrm{Tc}$ is $T_{p}=6$ hours and the proposed biological half-life of the ${ }^{99 \mathrm{~m}} \mathrm{Tc}$ source is $T_{b}=1.5$ hours. This gives an effective half-life $T_{e}$ for the ${ }^{99 \mathrm{~m}} \mathrm{Tc}$ source of $1.2 \mathrm{hr}$. Next, the dose rate is given in units of $\mathrm{rad} / \mathrm{hr}$ as

$$
R_{i}=2.13\left(\frac{A}{m}\right) N_{i} E_{i} \phi_{i}(v \leftarrow r),
$$

where $\phi_{i}$ is the absorbed fraction of radiation from the source organ $r$ to the target organ $v$ and the value 2.13 is a conversion factor so that equation (2) is will be expressed in $\mathrm{rad} / \mathrm{hr}$. Since the equilibrium dose is given by $\Delta_{i}=2.13 N_{i} E_{i}$ equation (2) becomes

$$
R_{i}=\left(\frac{A}{m}\right) \Delta_{i} \phi_{i}(v \leftarrow r)
$$

Due to physical and biological decay of the radioactivity $A$, the dose rate will decrease accordingly. Supposing that $A$ decays at an exponential rate, equation (3) may be rewritten as 


$$
R_{i}=\left(\frac{A_{o} e^{-\lambda_{e} t}}{m}\right) \Delta_{i} \phi_{i}(v \leftarrow r)
$$

where $A_{o}$ is the radioactivity in the target organ. To obtain the dose of radiation absorbed, equation (4) is integrated over the interval $0 \leq t<\infty$ giving

$$
D_{i}^{r a d}=\frac{A_{o}}{m} \Delta_{i} \phi_{i}(v \leftarrow r) \int_{0}^{\infty} e^{-\lambda_{e} t} d t=\frac{1}{\lambda_{e}} \frac{A_{o}}{m} \Delta_{i} \phi_{i}(v \leftarrow r)
$$

Because the effective decay constant is related to the effective half-life by $\frac{1}{\lambda_{e}}=\frac{T_{e}}{\ln 2}=1.44 T_{e}$, equation (5) becomes

$$
D_{i}^{r a d}=1.44 T_{e} \frac{A_{o}}{m} \Delta_{i} \phi_{i}(v \leftarrow r)
$$

The sum of all the products of the equilibrium dose $\Delta_{i}$ and the absorbed fraction $\phi_{i}$ is takes into account the multiple types of radiation that a radionuclide may give off. Thus total radiation dose is expressed as

$$
D^{r a d}=1.44 \frac{A_{o}}{m} T_{e}\left[\sum_{i=1}^{n} \Delta_{i} \phi_{i}(v \leftarrow r)\right]
$$

Results for the major radiation types that ${ }^{99 \mathrm{~m}} \mathrm{Tc}$ releases can be found in Table 2. After the sum has been determined, $\tilde{A}$ can be substituted for $1.44 T_{e} A_{o}$, and $S$ for $\frac{1}{m} \sum_{i=1}^{n} \Delta_{i} \phi_{i}$, finally giving

$$
D^{r a d}=\tilde{A} S
$$

The values of $\tilde{A}=5,132.16 \mu C i$ and $S=5.25 \times 10^{-5} \frac{\mathrm{rad}}{\mu C i}$ yield a dose of 269.44 mrads.

Now the mass of the lungs must be found to determine the dose rate. This is done by using the calculations of Table 2 in the Appendix and exploiting the fact that $\frac{1}{m} \sum_{i=1}^{n} \Delta_{i} \phi_{i}=S=$ $5.25 \times 10^{-5} \frac{\mathrm{rad}}{\mu \mathrm{Ci}}$, i.e., $m=1,535.24 \mathrm{~g}$. After substituting all values into equation (4), the initial dose rate is determined to be $156 \mathrm{mrads} / \mathrm{hr}$. 


\section{DISCUSSION}

The MIRD formula has improved the accuracy of dosimetry calculations by reducing the number of assumptions needed to perform dosimetry calculations as opposed to the classic method of dosimetry (Early 90). However, the MIRD formula has proved to be limited by other factors. One of these limitations is the coefficient of variation, "This is a statistical limitation. A coefficient of variation of $50 \%$ or greater represents a considerable uncertainty in the estimate of the absorbed fraction" (Early 90). Other limitations include biological calculation factors such as the kidney model not being divided into cortex and medulla, the bladder and stomach being a fixed size, (Early 90) and the fact that the MIRD formula presupposes that the source is uniformly distributed within a standard-sized organ, which is subject to much patient variation" (Early 92). It is imperative that these factors are taken into account, and that the dosimetrist be knowledgeable of the assumptions and limitations (Early 92). With the invention of more powerful computers and additional formulas to take limitations such as the coefficient of variation, organ size and shape, and the uniform distribution of the radionuclide dosimetry, calculations have become far more accurate than the MIRD formula used in this project.

\section{CONCLUSION AND RECOMMENDATIONS}

The project was successful in the calculation of the absorbed dose of radiation from the target organ and the initial dose rate. The calculated dose of radiation was 269.44 mrads and the calculated initial dose rate was $156 \mathrm{mrads} / \mathrm{hr}$. This problem however, does not account for other dose contributions from other source organs to the target organ, and only accounts for the dose contribution of the target organ to itself. These additional dose contributions would have proved negligible as the remaining $1 \%$ of uptake would have been distributed among the organs 
in which ${ }^{99 \mathrm{~m}}$ Tc-MAA implants. These organs would have included the kidneys, liver, ovaries or testes, and the whole body. Although negligible in this project, future projects could account for these additional dose contributions from organs other than the target organ.

\section{NOMENCLATURE}

\begin{tabular}{|c|c|c|}
\hline Symbol & Description & Value/Unit \\
\hline$t$ & Time & Hours $(h r)$ \\
\hline$T_{e}$ & Effective half-life & $1.2 \mathrm{hr}$ \\
\hline$T_{p}$ & Physical half-life & $6 h r$ \\
\hline$T_{b}$ & Biological half-life & $1.5 \mathrm{hr}$ \\
\hline$A$ & Radioactivity & Micro-Curie $(\mu C i)$ \\
\hline$A_{o}$ & Radioactivity in target organ & $2,970 \mu C i$ \\
\hline$\tilde{A}$ & $1.44 T_{e} A_{o}$ & $5,132.16 \mu C i$ \\
\hline$S$ & $\frac{1}{m} \sum_{i=1}^{n} \Delta_{i} \phi_{i}$ & $5.25 \times 10^{-5} \frac{\mathrm{rad}}{\mu C i}$ \\
\hline$m$ & Mass of target organ & $1,535.24 \mathrm{~g}$ \\
\hline$N_{i}$ & $\begin{array}{l}\text { Fraction of quanta emitted per disintegration for the } \\
i \text { th radiation }\end{array}$ & - \\
\hline$E_{i}$ & Energy of the emitted quanta for the $i$ th radiation & Mega electron volts $(\mathrm{MeV})$ \\
\hline$\phi_{i}(v \leftarrow r)$ & $\begin{array}{l}\text { Absorbed Fraction from source organ }(r) \text { to target } \\
\text { organ }(v) \text { for the } i \text { th radiation }\end{array}$ & - \\
\hline$\Delta_{i}$ & Equilibrium Dose for the $i$ th radiation & $\frac{g \cdot r a d}{\mu C i \cdot h r}$ \\
\hline$\lambda_{e}$ & Effective decay constant & 0.5775 \\
\hline$D_{i}$ & Cumulative radiation dose for the $i$ th radiation & $\mathrm{rad}$ \\
\hline$D$ & Total radiation dose & $\mathrm{rad}$ \\
\hline
\end{tabular}




\begin{tabular}{|c|c|c|}
\hline Symbol & Name / Unit & Conversion \\
\hline$C i$ & Curie / Radioactivity & $\begin{array}{l}3.7 \times 10^{7} d p s \\
\text { (disintegrations per second) }\end{array}$ \\
\hline$B q$ & $\begin{array}{l}\text { Becquerel / } \\
\text { Radioactivity }\end{array}$ & $2.703 \times 10^{-11} \mathrm{Ci}$ \\
\hline$M e V$ & $\begin{array}{l}\text { Million electron volts / } \\
\text { Energy }\end{array}$ & $1.602 \times 10^{-6} \mathrm{erg}$ \\
\hline rad & Rad / Energy & $100 \mathrm{erg} / \mathrm{g}$ \\
\hline Gy & Gray / Energy & $100 \mathrm{rad}$ \\
\hline
\end{tabular}

\section{REFERENCES}

Chandra, Ramesh. Introductory Physics of Nuclear Medicine. 4th ed. Philadelphia: Lea \& Febiger, 1992.

Early, Paul J. and Sodee, D. Bruce. Principles and Practices of Nuclear Medicine. 2nd ed. St. Louis: Mosby, 1995.

Saha, Gopal B. Fundamentals of Nuclear Pharmacy. 4th ed. New York: Springer, 1998. 


\section{APPENDIX: TABLES}

\begin{tabular}{|c|c|c|}
\hline Stage & $\begin{array}{l}\text { Dose Range } \\
\text { rads (Gy) }\end{array}$ & Symptoms \\
\hline 1 & $0-200(0-2)$ & Usually unobservable \\
\hline 2 & $150-400(1.5-4)$ & $\begin{array}{l}\text { Transient nausea and vomiting; some } \\
\text { evidence of damage to hematopoietic } \\
\text { system, recovering in } 1 \text { to } 2 \text { months }\end{array}$ \\
\hline 3 & $350-600(3.5-6)$ & $\begin{array}{l}\text { Severe damage to hematopoietic } \\
\text { system; bone marrow transplant } \\
\text { essential; survival chances, moderate }\end{array}$ \\
\hline 4 & $550-1000(5.5-10)$ & $\begin{array}{l}\text { Gastrointestinal damage; severe } \\
\text { nausea, vomiting and diarrhea; very } \\
\text { small chance of recovery; death } \\
\text { follows in } 10-24 \text { days }\end{array}$ \\
\hline 5 & 1000 and above (10 and higher) & $\begin{array}{l}\text { Confusion, shock, burning sensation; } \\
\text { death follows within hours }\end{array}$ \\
\hline
\end{tabular}

Table 1: Stages of radiation overdose with corresponding dose ranges and symptoms from Ref. (Early).

\begin{tabular}{|cccc|}
\hline Radiation & $\Delta_{i}$ & $\phi_{i}$ & $\Delta_{i} \phi_{i}$ \\
\hline $140-\mathrm{keV}$ photon & 0.2640 & 0.160 & 0.0422 \\
\hline $\mathrm{X}$ rays $(20 \mathrm{keV})$ & 0.0031 & 0.784 & 0.0024 \\
\hline Electrons & 0.0360 & 1.000 & 0.0360 \\
\hline & & Total $\left(\frac{g \cdot \mathrm{rad}}{\mu \mathrm{Ci}}\right):$ & 0.0806 \\
\hline
\end{tabular}

Table 2: Major forms of radiation associated with ${ }^{99 \mathrm{~m}} \mathrm{Tc}-\mathrm{MAA}$ and their associated equilibrium dose and absorbed fraction from Ref. (Saha). 